\title{
TEXAS 2050
}

\section{IAN CAINE}

University of Texas At San Antonio

\section{CARLOS SERRANO}

University of Texas At San Antonio

By the year 2050 the United States population will increase by half, with $70 \%$ living in a megaregion (Regional Plan Association, 2006). These numbers emphasize the critical link between large-scale territorial expansion and the prospects for successful urbanism. Currently 11 megaregions exist in the U.S., each bound together by a unique mixture of demographics, infrastructure, culture, and environment. As each megaregion grows, it must identify and leverage critical infrastructures that are capable of binding geographies and increasing efficiencies. This project speculates about one such strategy for the emerging megaregion known as the Texas Triangle.

The Texas Triangle is an expanding megaregion that boasts 5 of the 10 fastest growing cities in the U.S. including Dallas, Fort Worth, San Antonio, Austin and Houston (Carlyle, 2015). The population of the 36 largest urban areas in Texas is projected to double from 18 to 36 million by 2050 . This circumstance also doubles the land area given current densities, which average 2600 people per square mile. This residential concentration falls well below the level necessary to support investments in mass transit and high speed rail. As population in the Texas Triangle grows and geographies expand, the megaregion has the opportunity to re-organize itself along a high speed rail corridor. Rail infrastructure certainly has an uncertain political future in the United States. Still, the possibilities that the infrastructure offers to bind territories like the Texas Triangle are difficult to ignore. So what

\section{TRENTON TUNKS}

University of Texas At San Antonio would it take to implement high-speed rail in Texas? And how would it restructure growth in the megaregion?

This project seeks to answer these two questions, concentrating all projected population gains for the 36 largest urbanized areas in Texas into a continuous megaregional corridor, supported by high speed rail infrastructure. The rail corridor consists of 12 stations, all residing within the Texas Triangle. 4 of the stations are located within the major urbanized areas of Dallas, Fort Worth, Houston and San Antonio. The plan calls for these cities to absorb the projected growth through increased density rather than geographic expansion. This is accommodated through a mix of infill development and mass transit. The remaining 8 stations, which absorb all projected growth from the outlying areas, are placed in existing smaller urban areas within the Texas Triangle. These sites are transformed into Transit-Oriented-Developments with densities of approximately 9,000 people per square mile, which approximates the residential concentration in Santa Monica, California. The plan ultimately doubles the population with no increase in land area.

\section{Bibliography}

"American Fact Finder," www.census.gov (accessed July 1, 2015).

Burleson, Andrew, "The Routes," neoHOUSTON.com (accessed July 15, 2015)

Carlyle, Erin, “America's Fastest-Growing Cities 2015," Forbes, 27 January 2015, http://www.forbes. com/sites/erincarlyle/2015/01/27/americas-fastest-growing-cities-2015/

(accessed July 3, 2015).

Hagler, Yoav, "America 2050: Defining U.S. Megaregions," Regional Plan Association, http://www. america2050.org/upload/2010/09/2050_Defining_US_Megaregions.pdf (accessed June 15, 2015).

"Office of the State Demographer," www.osd.state. tx.us (accessed June 25, 2015).

Regional Plan Association, “America 2050: A Prospectus," New York, Sept 2006, http://www. america2050.org/pdf/America2050prospectus. pdf (accessed July 1, 2015). 
TEXAS 2050

The Importance of Megaregional Growth

$70 \%$ living in a megaregeion (Regional Plan Association, 2006). These numbers emphasize the crucial link between large-scale territorial
expansion and the prospects for successful urbanism. Currenty 1 .

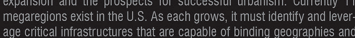

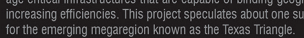

Projecting Growth and Density in the Texas Triangle

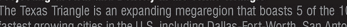

niio, Austin and Houston. The population of the 36 largest urban areas in

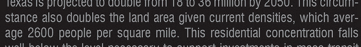

Well below the level necessary to support investiments in mass transit

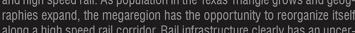

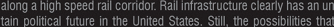

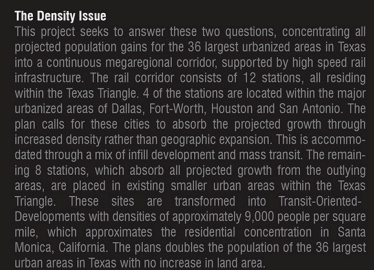

THE 36 LARGEST EXISTING URBAN AREAS IN TEXAS NOW AGCOMODATE 18.9M PEOPLE AT LOW DENSITY

existing whan areas at low density

\section{9}

total population
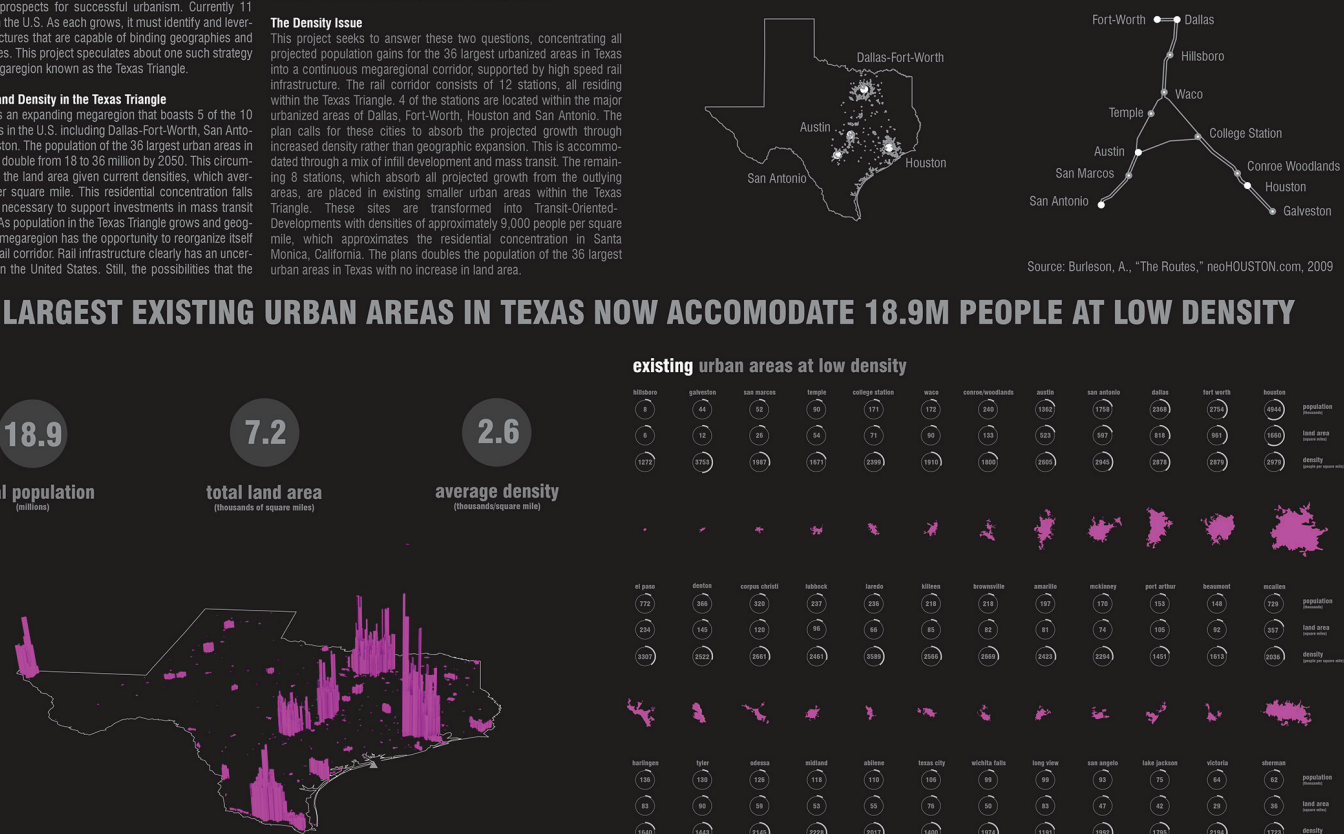

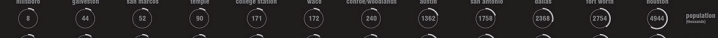

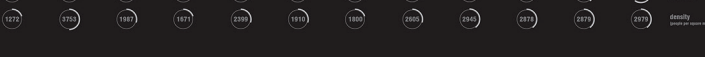

AT GURRENT DENSITIES THE PROJEGTED POPULATION GROWTH WILL DOUBLE LAND AREA BY 2050

projected unken areas at low densit.

$$
36.3
$$

total population
13.8

total land area
2.6

average density
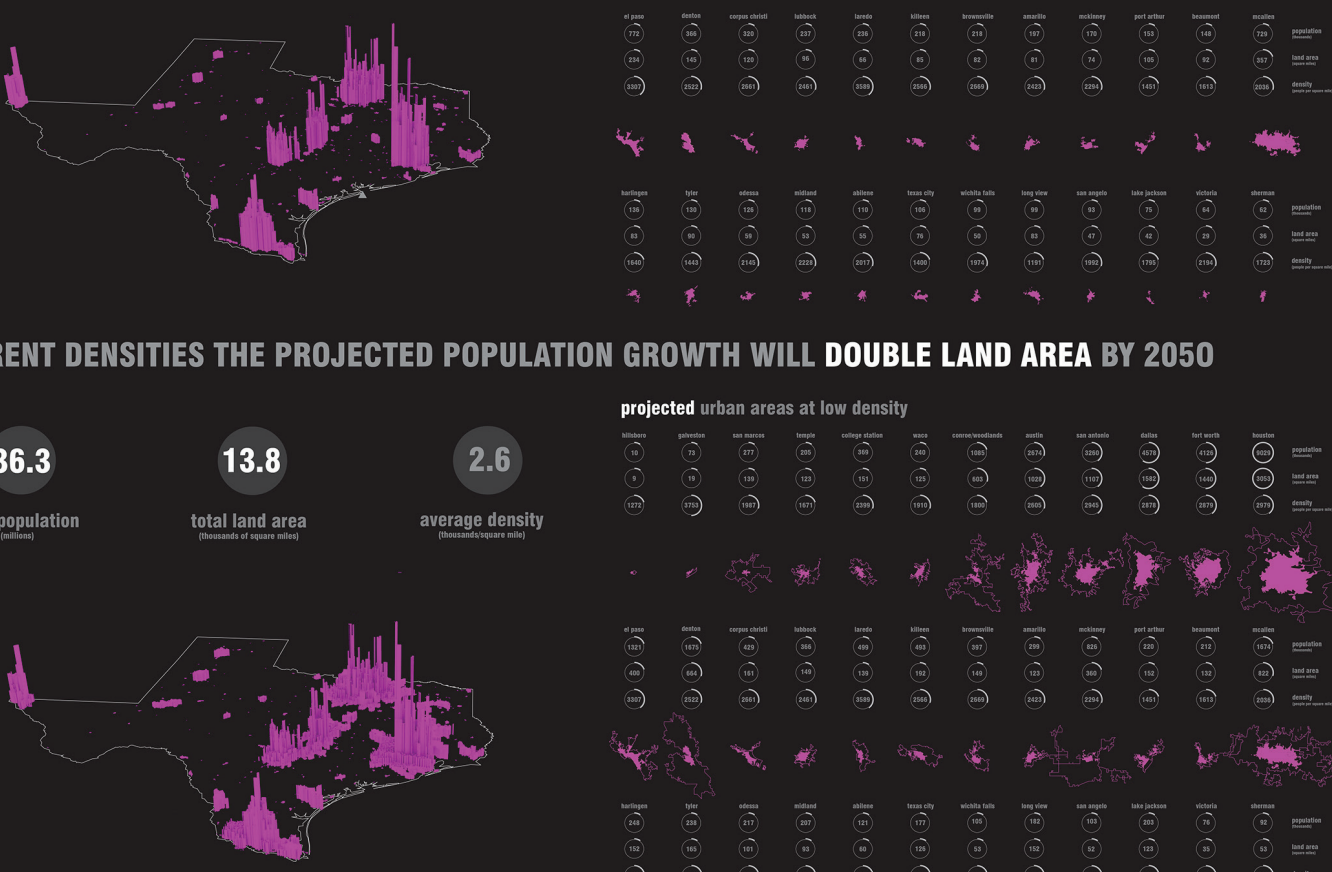

PROPOSED RAIL GORRIDOR ALLOWS 8 URBAN AREAS TO ABSORB GROWTH WITH NO INGREASE IN LAND AREA

proposed urban areas at increased density
36.3
7.2
5.1

total population

total land area

average density

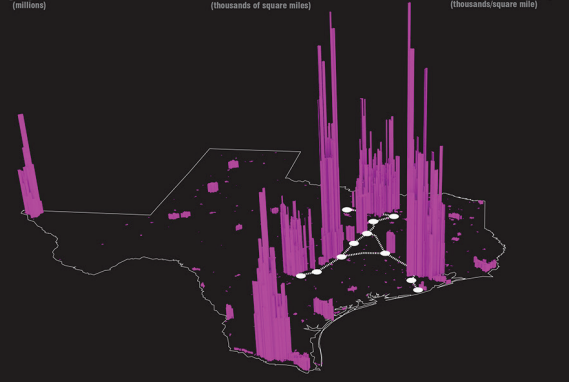

